\title{
A EXPERIÊNCIA MINEIRA NA IMPLANTAÇÃO DE DISTRITOS INDUSTRIAIS EM MUNICÍPIOS DE PEQUENO PORTE: O CASO DE ELÓI MENDES ${ }^{1}$
}

Elias Mendes Oliveira ${ }^{2}$

\section{Resumo}

Os Distritos Industriais consistem em espaços previamente preparados para receber plantas industriais. A implantação deste tipo de espaço produtivo constituiu uma estratégia utilizada em diversos países, dentre eles o Brasil, para dinamizar suas economias, reabilitar regiões estagnadas, ou promover a eqüidade espacial do território. Dentre os estados brasileiros, Minas Gerais foi pioneiro na sua implementação. O Distrito Industrial de Elói Mendes, fruto da parceria do governo estadual e municipal, na década de 1970, tem sua lógica de implantação na localização geográfica e na dinâmica da microrregião a que pertence o município.

Palavras-chaves: Distritos Industriais; industrialização; localização industrial.

\begin{abstract}
Industrial Districts are spaces previously prepared to receive industrial plants. Implantation of this type of production space was a strategy used by many countries, such as Brazil, to move its economy, rehabilitate economically depressed regions, or promote territory equity. Among Brazilian states, Minas Gerais was the first in its implantation. The Industrial District of Elói Mendes results from a partnership between state and local government, in 1970 's. Its implantation was based on the geographic localization and growth of the micro region.
\end{abstract}

Key-words: Industrial Districts; industrialization; industrial localization.

\section{Introdução}

\footnotetext{
${ }^{1}$ Trabalho de conclusão de curso de Geografia da Universidade Federal de Viçosa (UFV) - set. 2006.

${ }^{2}$ Universidade Federal de Alfenas (Unifal - MG). emendesoliveira@yahoo.com.br
} 
Dentre as formas de organização espacial da indústria, que, atualmente, tem sido evidenciada nos debates acadêmicos, estão os Distritos Industriais (DI's). A primeira noção de DI's surgiu na Inglaterra, no final do século XIX, para designar "concentrações de pequenas e médias empresas (PME's) ao redor dos grandes centros industriais" (HISSA, 2003).

Nesses distritos, as empresas de menor porte eram beneficiadas por uma série de fatores (economias externas), como o acesso à infra-estrutura, a presença de mão-de-obra treinada, a possibilidade de um bom relacionamento entre as firmas, dentre outros elementos. Tudo isso possibilitou às empresas de menor porte uma considerável produtividade, o que, segundo Hissa (2003), garantiu um grande desenvolvimento social e econômico à Inglaterra no século XIX.

Oliveira (1976) define os DI's como sendo uma área industrial onde o planejamento promove a implantação de infra-estrutura necessária ao desenvolvimento industrial. São, portanto, elementos de ordenação espacial e social, desenvolvimento industrial e intervenção do estado na organização do espaço. Além disto, é o locus e um dos mecanismos da materialização do processo de industrialização e das relações industriais.

Já para Markusen (1995), um DI é uma área espacialmente delimitada, com uma nova orientação de atividade econômica de exportação e especialização definida, seja ela relacionada à base de recursos naturais, ou a certos tipos de indústria ou serviços.

Após a Segunda Guerra Mundial, de acordo com Oliveira (1976), vários países usaram desses instrumentos para fortalecer a atividade industrial. Os DI's foram utilizados para atingir vários objetivos: eliminar as disparidades regionais e desenvolver a economia local (Itália); acelerar o crescimento industrial (EUA); reabilitar regiões economicamente debilitadas (Reino Unido); incentivar pequenas indústrias (Índia); atrair capital estrangeiro (Porto Rico); descongestionar os centros industriais (México); e ordenar a expansão industrial.

Os DI's derivam das transformações da atividade industrial, tanto em nível da racionalização da produção e de introdução de inovações tecnológicas, como de estrutura organizacional, e, de certa forma, com o tempo, tornam-se espaços produtivos e irradiadores de inovação e tecnologia, influenciando outros espaços produtivos e até mesmo a organização espacial regional e nacional. 
Para as empresas, a (re)alocação ou instalação de unidades nesses espaços constitui um modo de fuga dos altos preços dos terrenos nas áreas centrais das cidades, evitando transtornos ambientais, e facilitando a circulação de seus produtos, matérias-primas e dos trabalhadores. Além disso, terão a possibilidade de conseguir algum tipo de incentivo e poderão usufruir o ambiente produtivo dos DI's, tecendo parcerias, unindo forças por melhores condições de produção. Deste modo, segundo Carlos (2001), as indústrias atuam na produção do espaço urbano, que se transforma para atender as necessidades do processo produtivo e de suas relações (circulação, distribuição e troca).

\section{A Experiência Mineira na Implantação de Distritos Industriais}

No Brasil, os DI's foram construídos objetivando descentralizar e descongestionar o crescimento industrial das áreas centrais das cidades, evitando que cidades economicamente emergentes viessem apresentar problemas como os encontrados em São Paulo (SP) e Rio de Janeiro (RJ). Também, visavam incentivar a localização industrial em áreas previamente planejadas pelos governos, desenvolvendo áreas atrasadas, reduzindo desníveis regionais e ampliando o mercado consumidor.

Segundo Oliveira (1976), existiam duas estratégias básicas na criação dos DI’s: a primeira era a atração de indústrias para novas áreas, devido ao congestionamento e a localização não planejada nos centros das cidades. A segunda, tinha o intuito de criar uma “eqüidade" espacial, implantando e promovendo novas regiões de localização industrial. Os DI's exerceriam o papel de gerar novos pólos, irradiando crescimento industrial em diferentes escalas.

Na década de 1970, o Brasil contava com 46 DI's (FREITAS, 1995), abrigando várias empresas, estando mais concentrados na região Sudeste (21) e Nordeste (16). A forte concentração dos DI's no Sudeste pode ser explicada pelo crescimento industrial e pela aglomeração produtiva dessa região. Já no Nordeste, pode ser elucidado pela explícita estratégia de planejamento visando gerar crescimento industrial.

O estado de Minas Gerais foi o pioneiro na implantação deste tipo de aglomerado industrial, a partir da criação do Distrito Industrial Coronel Juventino Dias, em Contagem, em 1940. De acordo com Rodrigues (1983), começa a ocorrer na década de 1940, um processo de 
indução à industrialização pelo estado de Minas Gerais, adotando políticas desenvolvimentistas, seguindo o modelo nacional.

Aliados a isso, foram criados planos de recuperação econômica e fomento de produção e infra-estrutura (hidrelétricas, estradas, dentre outros) para instalação e crescimento das indústrias já existentes. Concomitantemente, houve a criação de empresas estatais como a Companhia Vale do Rio Doce e a Usiminas, indústrias de base responsáveis pelo desenvolvimento de outras atividades.

$\mathrm{Na}$ década de 1950, a economia mineira mostrava traços marcantes na atividade industrial, a partir da participação do capital estrangeiro e nacional. Neste período, instalaramse importantes empresas como a Belgo-Mineira, Mannesman, Alcan, Cominci e outras. Esses investimentos ocorreram em função da política de substituição das importações, implantados pelo governo federal, resultando em uma ampliação do parque industrial e da produção brasileira.

Já na década de 1970, a industrialização brasileira foi marcada pelo planejamento do governo militar e pela entrada de investimentos estrangeiros. Houve um grande desenvolvimento no parque industrial brasileiro, com a vinda de empresas motrizes, que contribuíram para a diversificação e o crescimento da economia nacional.

Foi neste contexto e para dar prosseguimento a esta política de desenvolvimento, que o governo mineiro criou a Companhia dos Distritos Industriais de Minas Gerais (CDI-MG), o Instituto de Desenvolvimento Industrial (INDI) e o Banco de Desenvolvimento de Minas Gerais (BDMG). Como conseqüência, obteve-se um avanço e um dinamismo em seu parque industrial.

A CDI-MG ${ }^{3}$ foi responsável por promover a criação de DI's em outras partes do estado, avaliando as áreas onde seria interessante a introdução desse tipo de organização industrial, e, por promover

estudos necessários à escolha mais adequada dentro do município, e, concluídos esses estudos preliminares, promovendo a compra ou desapropriação dos terrenos para posteriormente coordenar a execução das obras de infra-estrutura de acordo com os projetos de urbanização já concluídos. (OLIVEIRA, 1976, p. 51).

A CDI-MG concedia às empresas uma série de benefícios, como incentivos fiscais por determinado tempo e infra-estrutura para a implantação das unidades produtivas; fornece,

\footnotetext{
${ }^{3}$ A Companhia dos Distritos Industriais de Minas Gerais (CDI-MG), atualmente foi anexada à Companhia de Desenvolvimento Econômico de Minas Gerais (CODEMIG).
} 
também, apoio técnico às prefeituras municipais onde foram criados os distritos. Deste modo, a CDI - MG teve importante papel na industrialização de Minas Gerais, por implantar, ao longo de seus trinta anos, DI's em diferentes partes do estado.

Os dados mais recentes (CODEMIG, 2005) revelam que existem 51 DI's em Minas Gerais, sendo que 41 estão em funcionamento e 10 em implantação. Os que estão em funcionamento localizam-se nas cidades de Alfenas, Itabira, Pouso Alegre, Araguari, Itajubá, Rio Pomba, Araxá, Itaúna, Sabará, Belo Horizonte, Ituiutaba, Santa Luzia, Betim, Juiz de Fora, Santana do Paraíso, Conselheiro Lafaiete, Lavras, São João Del Rei, Contagem, Montes Claros, Sarzedo, Coronel Fabriciano, Nova Era, Sete Lagoas, Divinópolis, Passos, Três Pontas, Elói Mendes, Patrocínio, Uberaba, Extrema, Pedro Leopoldo, Uberlândia, Governador Valadares, Pirapora, Unaí, Ipatinga, Ponte Nova, Vespasiano, Varginha e Três Corações. Ainda estão em implantação os DI's das seguintes cidades: Barbacena, Manhuaçu, Santa Vitória, Barroso, Mariana, Ubá, Curvelo, Paraopeba, Ijaci e Santos Dumont. Os mais importantes economicamente estão localizados na Região Metropolitana de Belo Horizonte e em outros centros urbanos regionais como: Uberlândia, Uberaba, Passos, Varginha, Pouso Alegre, Itajubá, Sete Lagoas, Juiz de Fora e Governador Valadares.

Além dos DI's criados pela CDI-MG, alguns municípios mineiros tiveram a iniciativa de implantá-los por conta própria, objetivando atrair ou (re)organizar as indústrias na municipalidade, como é o caso de Viçosa, Visconde do Rio Branco e Paraguaçu.

Tanto os DI's implementados por iniciativa do governo estadual, por meio da CDIMG, quanto pelos governos municipais criaram políticas de incentivos à localização industrial, utilizando-se de isenções fiscais, doação de terrenos e infra-estrutura e da destinação de áreas próprias para a instalação de indústrias.

Cabe salientar que existe uma grande diferenciação dos DI's no estado de Minas Gerais, quer seja pelo tamanho, a importância das empresas instaladas, os tipos de empresas, a forma de criação, a estrutura física, a organização das empresas e da força de trabalho, e a região em que estão inseridos.

Independente do gestor ou mentor, os DI's abrigam várias empresas que são responsáveis por grande parte da produção e do emprego industrial, tornando-se o lócus privilegiado das indústrias. Também induziram o crescimento industrial de vários centros urbanos e a (re)organização dos espaços locais e, em alguns casos, regionais. O DI de Elói Mendes é exemplo de um DI que modificou a economia local. 


\section{A implantação de Distritos Industriais em municípios de pequeno porte: o caso de}

Elói Mendes.

O município de Elói Mendes está localizado no Sul de Minas Gerais, mais precisamente na microrregião de Varginha. Está distante $328 \mathrm{~km}$ de Belo Horizonte, $340 \mathrm{~km}$ de São Paulo, e $410 \mathrm{~km}$ do Rio de Janeiro. A cidade é formada unicamente por seu distritosede, sendo a $\mathrm{BR}$ - 491, que a liga aos municípios limítrofes de Varginha e Paraguaçu, e à rodovia Fernão Dias (BR - 381), a principal via de acesso. (Figura 01).

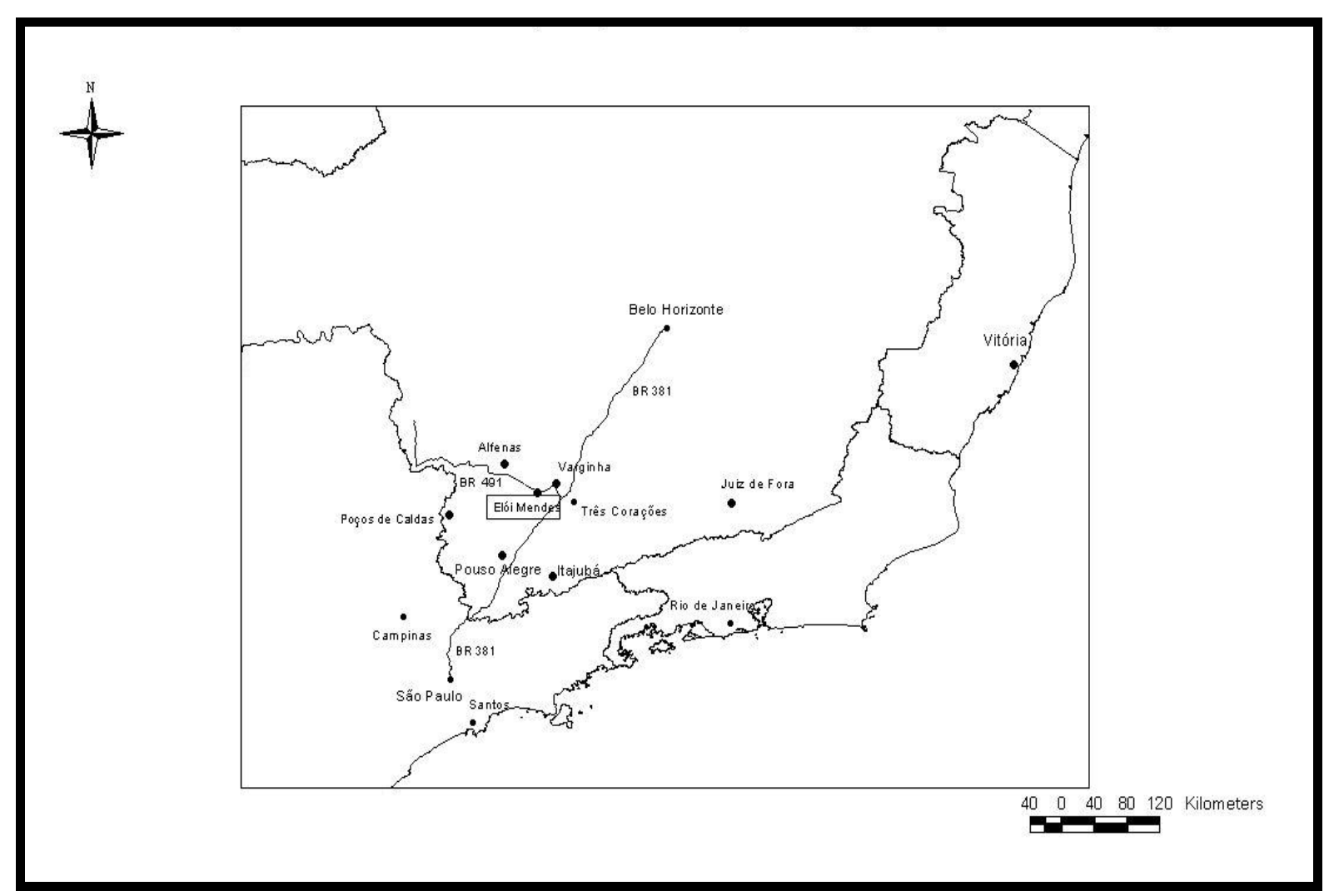

Figura 01: Localização do município de Elói Mendes (MG) em relação aos principais centros econômicos do país e da mesorregião do Sul de Minas - 2006.

Trata-se de em um município de pequeno porte, com 21.907 habitantes (IBGE, 2000), com 77, 7\% da população residindo na área urbana (IBGE, 2000). A maior parte da População Economicamente Ativa (PEA) dedica-se às atividades do setor terciário (44\%) (IBGE, 2000), seguindo a lógica da economia contemporânea. No entanto, vale ressaltar que a quantidade de pessoas empregadas no setor primário é expressiva $(39,1 \%)$ (IBGE, 2000), 
dado o peso histórico das atividades agrícolas na região, notadamente a cafeicultura e a criação de gado leiteiro.

Deste modo, a implantação de um DI em um município de pequeno porte, tradicionalmente ligado às atividades agropecuárias, sem grande expressão na economia mineira, torna-se um ponto intrigante, ainda mais por ter sido criado em parceria com o governo estadual, por meio de seu órgão de fomento (CDI-MG).

Na realidade, a implantação do DI em Elói Mendes é resultado da interação de uma série de fatores, que não se reduzem unicamente às articulações políticas locais, mas também à dinâmica da microrregião em que está localizado e à sua posição geográfica.

A localização geográfica privilegiada do município no território nacional apareceu como um fator estratégico para a criação deste tipo de espaço produtivo. Elói Mendes está localizado $328 \mathrm{~km}$ de Belo Horizonte e $340 \mathrm{~km}$ de São Paulo, logo está diretamente ligado aos fluxos de mercadorias e pessoas estabelecidos por meio da rodovia Fernão Dias (BR 381), que liga estes importantes centros econômicos, distante apenas $35 \mathrm{~km}$ da cidade.

O município encontra-se, ainda, bem posicionado em relação a cidades importantes no contexto do estado de Minas Gerais, como Juiz de Fora (299 km), Poços de Caldas (150 km), Pouso Alegre $(132 \mathrm{~km})$, Itajubá $(197 \mathrm{~km})$, Alfenas $(53 \mathrm{~km})$, Três Corações $(58 \mathrm{~km})$ e Varginha $(15 \mathrm{~km})$. A cidade do Rio de Janeiro, outro importante centro econômico, também não se encontra muito distante $(410 \mathrm{~km})$.

Assim, a criação de um DI em Elói Mendes representaria não só a facilidade de escoamento para importantes centros econômicos, mas também a oportunidade de exportação, uma vez que o município encontra-se não muito distante do Porto de Santos (SP) e de Sepetiba (RJ).

Além da localização geográfica privilegiada, a dinâmica socioespacial da microrregião de Varginha constituiu um segundo fator determinante para a implantação do DI no município.

A microrregião de Varginha é composta por 16 municípios: Boa Esperança, Campanha, Campo do Meio, Campos Gerais, Carmo da Cachoeira, Coqueiral, Elói Mendes, Guapé, Ilicínea, Monsenhor Paulo, Santana da Vargem, São Bento Abade, São Tomé das Letras, Três Corações, Três Pontas e Varginha. (Figura 02). 


\section{$+$}

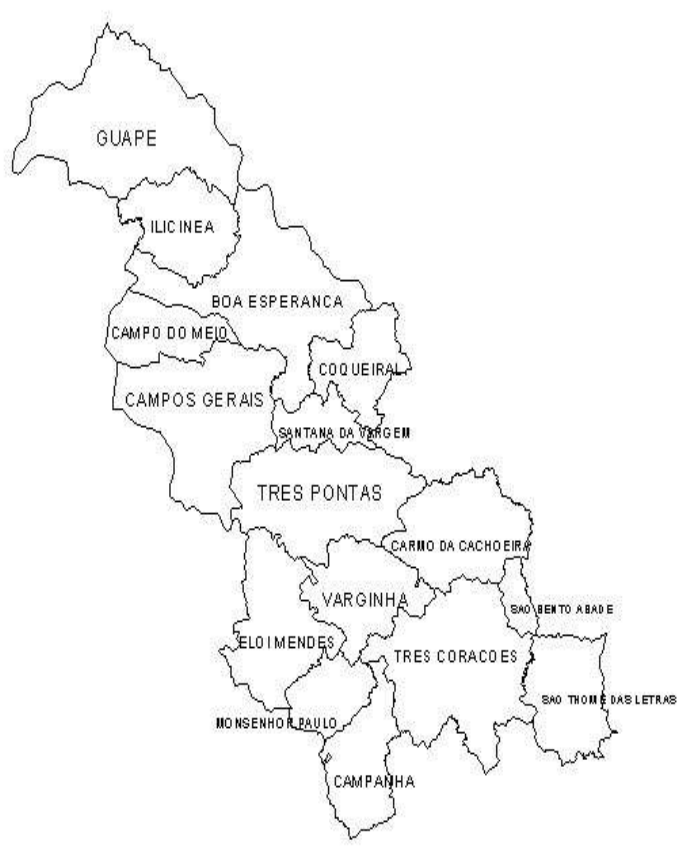

$40 \quad 40$ Kilometers

Figura 02: Divisão político-administrativa dos municípios que compõem a microrregião de Varginha (MG) - 2006.

Embora as atividades agropecuárias sejam muito fortes na microrregião, em função de sua posição de destaque na produção e comercialização de café, e ocupem, na maioria dos municípios, a maior parte da PEA (34, 1\%) (IBGE, 2000), é importante destacar a influência da rede de fluxos estabelecida pela Rodovia Fernão Dias (BR - 381), que passa por terras de Varginha, Três Corações, Carmo da Cachoeira e Campanha, municípios da microrregião. Esse fato provoca, pelo intenso fluxo, transformações espaciais e desdobramentos econômicos importantes que impactaram os municípios da microrregião. Foi neste contexto que municípios como Pouso Alegre, Três Corações, Varginha e Lavras tiveram um grande crescimento industrial e que o governo estadual, visualizando esta tendência, implantou DI's nos municípios de Varginha, Três Corações, Lavras, Pouso Alegre e Extrema, cortados pela rodovia.

O município de Varginha foi um dos mais influenciados pela rede de fluxos estabelecidos pela BR - 381, e passou a polarizar uma série de serviços e indústrias, aumentando o seu peso não só na microrregião da qual é centro, mas também na mesorregião do Sul de Minas. Para Amorim Filho et al (2000), o crescimento acelerado de Varginha pode, inclusive, tornar-se um fator de desequilíbrio regional. 
Elói Mendes, por ser o município mais próximo a Varginha, acabou sendo influenciado pela rede de fluxos estabelecidos por este município, assim como pelo eixo de desenvolvimento formado pela Fernão Dias. Além disso, a BR - 491, principal via de acesso a Elói Mendes, passa por importantes cidades do Sul de Minas, como Alfenas, Três Corações, Varginha e Guaxupé, constituindo, para Amorim Filho et al (2000), um dos eixos de desenvolvimento em Minas Gerais.

A proximidade ao centro mais dinâmico da microrregião e à $\mathrm{BR}$ - 381 atrai a atenção dos empresários, que poderão encontrar, num município de menor porte, mão-de-obra barata e incentivos decorrentes da iniciativa do poder público em promover a industrialização local.

O último fator preponderante para a instalação do DI em Elói Mendes diz respeito à articulação política de pessoas do próprio município, que negociaram com a CDI-MG, e com ela estabeleceram um convênio para a implantação deste tipo de organização da indústria na cidade.

As primeiras articulações entre a Prefeitura Municipal de Elói Mendes e a CDI - MG ocorreram entre 1973 - 1977, com o objetivo de desenvolver o município por meio da industrialização, buscando aumentar a oferta de empregos e a arrecadação municipal. Neste contexto, segundo Oliveira (1976), era comum a busca pela industrialização local pelos administradores públicos, visto que

$$
\begin{aligned}
& \text { a industrialização local tem sido encarada não somente ao fator multiplicador do } \\
& \text { emprego industrial como também a uma série de benefícios por ela gerados como a } \\
& \text { elevação da renda per capita do município, aumento dos gastos da população e } \\
& \text { conseqüente estímulo aos estabelecimentos comerciais e de serviços, elevação na } \\
& \text { arrecadação municipal, etc [...]. (OLIVEIRA, 1976, p. 22). }
\end{aligned}
$$

Com este intuito, aproveitando-se da iniciativa do governo estadual em industrializar o interior por meio da implantação de DI's, a Prefeitura firmou um convênio com a CDI-MG para a criação da área industrial da cidade.

No período compreendido entre 1977 - 1983, houve as permutas dos terrenos que iriam compor o DI, bem como foi assinado o contrato que estabeleceu as responsabilidades das partes envolvidas neste processo: a Prefeitura Municipal e a CDI-MG. Além disso, articulou-se a criação de bairros populares no município, como o Bairro Traituba (Companhia de Habitação - COHAB). Entre 1983 - 1988, o DI recebeu as primeiras indústrias, iniciando o ciclo de crescimento industrial no município. 
Assim, os fatores que explicam o interesse da CDI - MG em criar um DI em Elói Mendes, um município tradicionalmente ligado à agropecuária, vão desde a localização privilegiada deste no território nacional à articulação política local, até uma dinâmica microrregional favorável, devido à concentração de indústrias nos municípios de Varginha e Três Corações.

\section{O Convênio Firmado Entre a Prefeitura Municipal de Elói Mendes e A Cdi -Mg Para a Instalação do Distrito Industrial}

Em 1976, foi aprovada a Lei Municipal 1150/76 que dispõe sobre a aprovação do convênio entre a Prefeitura Municipal e a CDI - MG. Por este convênio, o poder público deveria adquirir e liberar em seu território uma área de cerca de $500.000 \mathrm{~m}^{2}$ e transferi-la para a CDIMG, que se encarregaria de escolher as áreas mais adequadas para a criação da área industrial no município, bem como elaborar e executar todas as obras urbanísticas necessárias, por conta própria ou por meio de concessionárias de serviços públicos. Deste modo, apenas a CDI-MG se encarregaria dos aspectos técnicos do projeto, ficando a Prefeitura impossibilitada de aprovar qualquer alteração sem o seu consentimento.

No entanto, foi no período posterior a 1977, que observamos avanços nas discussões em torno do DI. Estabeleceu-se que a melhor área para a instalação do distrito seria próxima ao núcleo urbano, junto à rodovia BR - 491 e à Estação de Tratamento de Água. Uma vez situado próximo à rodovia, as empresas teriam facilidades para escoar a sua produção. A proximidade ao núcleo urbano facilitaria a locomoção da mão-de-obra.

Sendo assim, por meio da Lei Municipal 1233/79, o poder público adquiriu, através de permuta com uma empresa, uma área de 60,5 hectares, junto à BR - 491, para a implantação da área industrial da cidade. Na negociação, o município cedeu à empresa um terreno com 145,2 hectares em um bairro rural do município, avaliado no mesmo valor.

A Lei Municipal 1241/79 aprovou a permuta de 59,3 hectares, contíguos àquele adquirido por meio da Lei Municipal 1233/79. Uma parcela deste imóvel iria compor, juntamente com o terreno já adquirido pela Prefeitura, o DI do município, enquanto outra parcela seria utilizada para a criação do núcleo residencial da Companhia de Habitação/COHAB (Bairro Traituba).

Uma vez adquirida a área onde seria instalado o distrito, foi preciso regularizar as negociações por meio de uma legislação específica e formalização em cartórios. A Lei Municipal 1252/79 autorizou a Prefeitura a transferir uma área de 35,1 hectares para a CDI - 
MG, para a construção do DI do município. Caso o terreno fosse utilizado com qualquer outra finalidade, retornaria ao patrimônio municipal. A Lei Municipal 1255/80 especificou que a transferência do terreno para a CDI - MG foi feita por meio de doação.

Na primeira metade dos anos 1980, iniciaram-se as obras de infra-estrutura na área do DI. Naquele momento foram abertas as vias de circulação interna e a via de acesso, a rede de saneamento básico e de abastecimento de água, as instalações elétricas, dentre outras.

A partir de 1986, as empresas começaram a construir suas plantas industriais no distrito. Estas firmas foram atraídas por uma série de fatores, dentre eles, a política de incentivos contidos na Lei Municipal 1407/86, que será discutida mais adiante.

No convênio firmado entre a Prefeitura Municipal e a CDI - MG, ficou evidente que a CDI - MG se encarregaria dos detalhes técnicos do empreendimento, analisando e aprovando os projetos de instalação de firmas, bem como qualquer outra alteração física em suas estruturas. À Prefeitura coube a tarefa de atrair as empresas, mediando as negociações entre estas e a CDI - MG, e a manutenção periódica das vias públicas, do sistema de abastecimento de água e de esgoto, da drenagem das águas pluviais e da limpeza.

\section{As políticas de incentivos e a atração de empresas}

Uma vez delimitada a área industrial no município, e disponibilizadas uma série de infra-estruturas essenciais para o funcionamento de indústrias, foi preciso criar outros mecanismos para a atração de empresas para o DI.

Primeiramente, convém ressaltar que a presença de uma área reservada às atividades industriais, espacialmente bem localizada no território nacional, já representa um grande atrativo às empresas. Uma vez instaladas em espaços apropriados, evitariam alguns transtornos que certamente teriam se estivessem no centro da cidade, como congestionamento do trânsito, poluição sonora, dentre outros. Além disso, a disponibilidade de água, energia elétrica e de vias de circulação adequadas constituem outros atrativos neste tipo de espaço.

No entanto, para tornar o distrito ainda mais atrativo, foi preciso que a Prefeitura aprovasse algumas leis de incentivos. Deste modo, em 1986, foi aprovada a Lei Municipal 1407/86, que regulamentou a política de incentivos tributários e de doação de terrenos. De acordo com o Art. $2^{\circ}$ desta lei, a Prefeitura concederia a isenção de tributos municipais, por 
um prazo de até dez anos, a todas as indústrias que se instalassem no município, desde que recrutassem dez ou mais empregados.

O Art. $3^{\circ}$ especificou as relações estabelecidas no DI. Pela lei, as empresas que quisessem levar suas plantas industriais para o distrito, deveriam, primeiramente, firmar um contrato particular com a CDI-MG, que avaliaria o projeto, podendo aprová-lo ou não. Uma vez aprovado, se a empresa não cumprisse os prazos e condições estabelecidas pela CDI-MG, reembolsaria ao município o valor estabelecido no contrato.

No Art. $4^{\circ}$ foi explicitado que se uma empresa solicitasse a doação de terreno, junto à CDI - MG, o município consignaria o prazo máximo de 180 dias para a implantação e operacionalização, sob pena de reversão do terreno, que retornaria ao patrimônio municipal.

Analisando a Lei Municipal 1407/86, que foi reafirmada pela Lei Municipal 168/91, podemos observar que a grande preocupação consistiu na geração de empregos para o município, e não em determinar um tipo específico de indústria para o DI.

Além da doação de terrenos e isenção de tributos municipais, as leis municipais 1407/86 e 168/95 estabeleceram, ainda, o auxílio financeiro do poder público na construção de galpões, que seria regulamentado por leis posteriores.

Várias outras leis foram criadas visando possibilitar ao município ou à Prefeitura a liberdade de negociação ou a doação de algum benefício fiscal, material ou financeiro às empresas que fossem se instalar no DI.

Em 2005, o governo municipal sancionou a Lei 894/05, que instituiu o Programa de Incentivo Empresarial (PROEM), atual política de incentivos de Elói Mendes. Esta lei tem como objetivo estimular e criar facilidades às empresas que pretendam implantar, ampliar ou realocar suas instalações no município, atentando para as áreas de expansão urbana ou o DI.

Esta lei prevê a cessão de terrenos por meio de comodato; a preparação destes terrenos, que envolvem desde obras de terraplanagem, até a mediação junto aos órgãos públicos e empresas de prestação de serviços essenciais para a execução das redes de abastecimento de água, coleta de esgotos, distribuição de energia elétrica e telecomunicações; desapropriação de imóveis com a finalidade específica de expansão industrial; e propiciar áreas e locais adequados para o funcionamento de novas empresas a serem instaladas, com o pagamento, provisório, de aluguéis dos imóveis utilizados para a instalação. 
Na cessão dos incentivos acima listados, a Prefeitura terá preferência pelas firmas que gerarem o maior número de empregos, além do uso de matérias-primas locais. Da mesma forma, observará os impactos ambientais que poderão resultar das atividades da empresa.

Em suma, as políticas de incentivos, desde que o momento em que o DI foi implantado, giraram em torno de incentivos fiscais municipais e doação de lotes e infraestrutura para a implantação das unidades industriais ou comerciais.

\section{Diagnóstico das atuais condições do Distrito Industrial de Elói Mendes}

O DI de Elói Mendes está localizado junto à margem direita (sentido Varginha - Elói Mendes) da BR - 491, a 1,4 km do entroncamento desta com a Avenida Dom Pedro II, principal via urbana do município. Possui uma área de 35,1 hectares. (Figura 03).

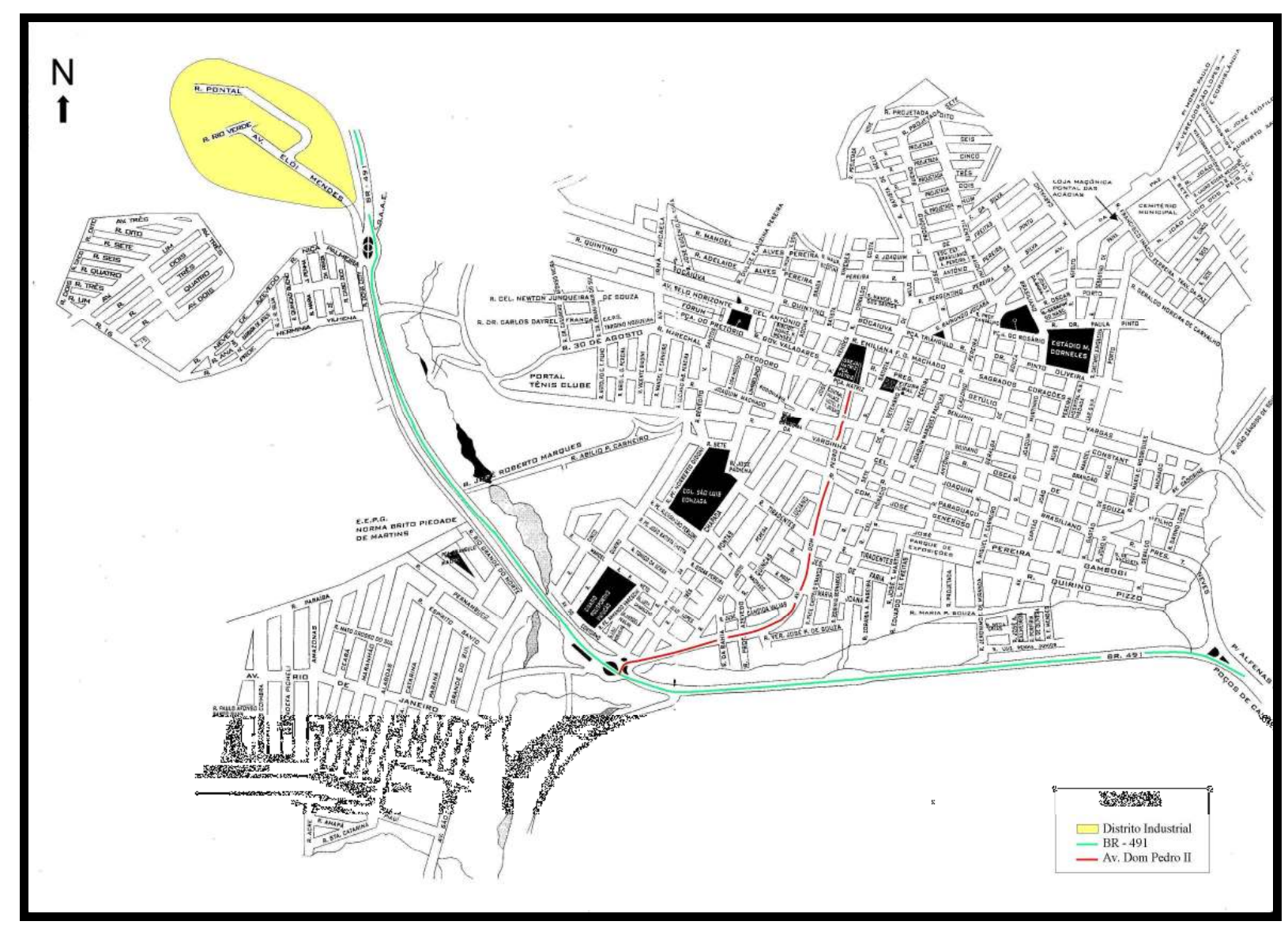

Figura 03: Localização do Distrito Industrial José Augusto Machado Filho na cidade de Elói Mendes (MG) - 2006.

Fonte: Prefeitura Municipal de Elói Mendes, 2006. 
A localização do distrito nesta área tinha uma lógica específica: uma vez próximo à rodovia, as empresas teriam maiores facilidades para a aquisição das matérias-primas, bem como o escoamento rápido de suas mercadorias. Além disso, por meio da $\mathrm{BR}-491$, o distrito estaria em comunicação com a rodovia Fernão Dias (BR - 381).

A proximidade à área central constitui outro ponto importante para a localização do distrito, que não poderia ser muito distante, evitando que os trabalhadores depreendessem muito tempo com transporte. Além disso, junto à cidade, seria mais fácil levar até a área distrital a infra-estrutura básica necessária ao funcionamento da indústria (energia, rede de água e esgoto, transporte coletivo, etc).

Quanto à sua estrutura, o traçado urbanístico inicial proposto pela CDI - MG previa um sistema viário com dois anéis internos e rampas suaves, que seriam destinadas às pequenas e médias empresas. Contudo, com a possibilidade de demanda por terrenos por empresas de maior porte, este traçado foi modificado, passando a ser constituído por uma via principal, que liga o DI à BR - 491, e duas secundárias. Recentemente, uma nova via de circulação foi aberta.

Todas as vias de circulação são asfaltadas, e sua manutenção periódica é de responsabilidade da Prefeitura. Durante os trabalhos de campo (abril de 2006), foi constatado que estas não apresentam boas condições, apresentando buracos.

\section{As empresas}

Atualmente, o DI é ocupado por nove empresas, que atuam em ramos diferenciados. Duas das firmas não constituem indústrias: a empresa Recrisul, que consiste em uma empresa de reciclagem; e a ANNA Café LTDA, que apenas revende café, não realizando nenhum tipo de processamento dos grãos. A tabela a seguir mostra as características das empresas que compõem o distrito eloiense.

Tabela 01: Caracterização Geral das Empresas que Compõem o DI de Elói Mendes

\begin{tabular}{|l|l|l|l|l|l|}
\hline Empresa & Produtos que fabrica & $\begin{array}{l}\text { Origem das } \\
\text { matérias- } \\
\text { primas }\end{array}$ & $\begin{array}{l}\text { Principais } \\
\text { destinos da } \\
\text { Produção }\end{array}$ & $\begin{array}{l}\text { Ano de } \\
\text { Instalação }\end{array}$ & $\begin{array}{l}\text { Incentivos } \\
\text { Obtidos }\end{array}$ \\
\hline $\begin{array}{l}\text { Alimentos } \\
\text { Agroindustrial } \\
\text { LTDA }\end{array}$ & $\begin{array}{l}\text { Beneficiamento de } \\
\text { arroz, produzindo } \\
\text { biscoitos e outros } \\
\text { produtos integrais }\end{array}$ & $\begin{array}{l}\text { Região Sul, } \\
\text { SP e MG }\end{array}$ & SP & 1995 & $\begin{array}{l}\text { Cessão de } \\
\text { terreno }\end{array}$ \\
\hline
\end{tabular}




\begin{tabular}{|c|c|c|c|c|c|}
\hline $\begin{array}{l}\text { ANNA } \\
\text { Comércio de } \\
\text { Café LTDA }\end{array}$ & Revenda de Café & $\begin{array}{l}\text { Sul de } \\
\text { Minas }\end{array}$ & SP & 2000 & $\begin{array}{l}\text { Ajuda } \\
\text { financeira da } \\
\text { Prefeitura para } \\
\text { o fechamento } \\
\text { do terreno }\end{array}$ \\
\hline $\begin{array}{l}\text { Armazéns } \\
\text { Gerais } \\
\text { Carapina }\end{array}$ & $\begin{array}{l}\text { Armazenamento e } \\
\text { processamento de } \\
\text { grãos de café para a } \\
\text { exportação }\end{array}$ & $\begin{array}{l}\text { Sul de } \\
\text { Minas }\end{array}$ & $\begin{array}{l}\text { Estados } \\
\text { Unidos, } \\
\text { Canadá, } \\
\text { União } \\
\text { Européia e } \\
\text { Oriente } \\
\text { Médio }\end{array}$ & 1989 & $\begin{array}{l}\text { Cessão de } \\
\text { terrenos }\end{array}$ \\
\hline $\begin{array}{l}\text { C.A. Petrone } \\
\text { LTDA }\end{array}$ & $\begin{array}{l}\text { Cartões magnéticos, } \\
\text { avisos de porta para } \\
\text { hotéis e cartões para } \\
\text { transportes coletivos }\end{array}$ & Cotia (SP) & $\begin{array}{l}\text { Região } \\
\text { Sudeste }\end{array}$ & 1988 & $\begin{array}{l}\text { Cessão de } \\
\text { terreno }\end{array}$ \\
\hline G.R. Móveis & $\begin{array}{l}\text { Mesas de cozinha e } \\
\text { móveis tubulares }\end{array}$ & SP & $\begin{array}{l}\text { Sul de } \\
\text { Minas }\end{array}$ & 1998 & $\begin{array}{l}\text { Cessão de } \\
\text { terreno }\end{array}$ \\
\hline Recrisul & $\begin{array}{l}\text { Coleta de produtos } \\
\text { recicláveis } \\
\text { (alumínios, vidros, } \\
\text { papéis, plásticos, } \\
\text { etc...) }\end{array}$ & Elói Mendes & $\begin{array}{l}\text { Sul e Zona } \\
\text { da Mata } \\
\text { mineira }\end{array}$ & 2002 & Nenhum \\
\hline $\begin{array}{l}\text { Souza Cambos } \\
\text { Confecções }\end{array}$ & $\begin{array}{l}\text { Calças, jaquetas, } \\
\text { bermudas, camisetas } \\
\text { e outras peças de } \\
\text { roupa em jeans }\end{array}$ & $\begin{array}{l}\text { SP, CE, SC, } \\
\text { RN, PE e } \\
\text { MG }\end{array}$ & SP & 2000 & Nenhum \\
\hline $\begin{array}{l}\text { Tubominas } \\
\text { Indústria e } \\
\text { Comércio } \\
\text { LTDA }\end{array}$ & $\begin{array}{l}\text { Tubetes de papelão } \\
\text { reciclado }\end{array}$ & $\mathrm{SP}, \mathrm{BH}$ e SC & $\begin{array}{l}\text { Região } \\
\text { Sudeste, Sul } \\
\text { e AM }\end{array}$ & 1986 & $\begin{array}{l}\text { Ajuda para a } \\
\text { construção de } \\
\text { um galpão }\end{array}$ \\
\hline $\begin{array}{l}\text { Vênus Têxtil } \\
\text { LTDA }\end{array}$ & $\begin{array}{l}\text { Linha para costura de } \\
\text { uso doméstico e } \\
\text { industrial. }\end{array}$ & $\mathrm{PB}$ e SP & $\begin{array}{l}\text { Todo o } \\
\text { Brasil, } \\
\text { Argentina, } \\
\text { Peru e } \\
\text { Chile. }\end{array}$ & 1996 & $\begin{array}{l}\text { Construção de } \\
\text { Galpão e } \\
\text { cessão de } \\
\text { terrenos }\end{array}$ \\
\hline
\end{tabular}


As empresas instaladas no DI de Elói Mendes empregam 992 pessoas, o que corresponde a 9,95\% da PEA do município, e 58,8\% do pessoal que trabalha no setor industrial, no ano de 2000 (dados mais recentes). Deste modo, observamos o peso que as empresas presentes no distrito desempenham nas atividades industriais do município, empregando mais da metade do pessoal do setor secundário.

A maior parte dos empregados pertence ao sexo masculino, 69,95\% contra 30,05\% do sexo feminino, o que pode ser explicado pelos tipos de atividades exercidas no distrito. Algumas empresas necessitam que seus funcionários carreguem um volume de carga expressivo (café, tubos, alumínio prensado, madeira, dentre outros), disponibilizando mais empregos para indivíduos do sexo masculino.

Os trabalhadores estão concentrados nas etapas de produção, que absorvem 89,6\% da mão-de-obra. Esta característica pode ser explicada pelo pequeno volume de tecnologia empregado nas atividades produtivas e pelo fato de que algumas empresas, pelas suas características produtivas, necessitam de muita mão-de-obra na produção. Além disso, como as empresas são de pequeno porte, geralmente os proprietários ficam encarregados das atividades administrativas.

\section{Considerações Finais}

O espaço geográfico consiste em um produto social, e caracteriza-se por seu dinamismo, ou seja, está em constante mudança. Os agentes políticos e econômicos com interesses diversos e utilizando-se dos mais variados discursos (sustentabilidade, desenvolvimentismo, etc...), modelam esse espaço. Os discursos que envolvem a industrialização local em Elói Mendes foram e continuam sendo empregados no que se referem às ações sobre o espaço, dada às rápidas transformações socioespaciais geradas pela indústria.

A implantação de um DI em Elói Mendes, um município de pequeno porte, com tradição em atividades agrícolas e de pequeno peso na economia estadual e microrregional reflete as ações das elites econômicas e políticas, traduzindo uma nítida intervenção do estado no espaço. Deste modo, o DI de Elói Mendes é o resultado da conjugação de fatores de ordem local, microrregional, estadual e nacional, pois é preciso compreendê-lo em diferentes escalas, que estão imbricadas. 
No âmbito nacional, o movimento de desconcentração industrial do eixo Rio - São Paulo, que convivia com os problemas da economia de aglomeração, aparece como um fator importante, já que muitas empresas deixaram este eixo em busca de áreas onde tivessem menores custos de produção, maximizando seus lucros.

No que concerne ao estado de Minas Gerais, a industrialização do interior aparece como um objetivo importante em suas políticas, que visavam modernizar e dinamizar sua economia, aumentando sua relevância em relação aos estados mais dinâmicos do país. Neste cenário surgem vários pequenos DI’s, dentre eles o de Elói Mendes.

A microrregião de Varginha, na qual está o município de Elói Mendes, foi diretamente afetada pelo movimento de desconcentração industrial de São Paulo, principalmente pela influência da BR - 381. Esta influência dinamizou a economia de alguns dos municípios entrecortados por esta rodovia, como Lavras, Pouso Alegre, Três Corações e Varginha, tornando-se um dos eixos de desenvolvimento de Minas Gerais.

O município de Varginha foi um dos mais influenciados pela rede de fluxos estabelecidos pela BR - 381, e passou a polarizar uma série de serviços e indústrias, aumentando o seu peso não só na microrregião da qual é centro, mas também na mesorregião do Sul de Minas.

Por ser o município mais próximo a Varginha, Elói Mendes acabou sendo influenciado pela rede de fluxos estabelecidos por este município, assim como pelo eixo de desenvolvimento formado pela $\mathrm{BR}$ - 491, que liga importantes municípios da mesorregião do Sul de Minas, como Três Corações, Alfenas e Guaxupé.

No que concerne aos fatores locais que possibilitaram a implantação do DI de Elói Mendes, podemos citar a ação dos agentes políticos, responsáveis pelas negociações com a CDI-MG, visando desenvolver o município por meio da industrialização local.

Já as empresas que se instalaram no DI de Elói Mendes, o fizeram por motivos diversos, como a localização do município na região cafeeira do Sul de Minas, fugindo dos problemas encontrados na Grande São Paulo ou pelos incentivos concedidos no DI. Tratam-se de empresas de pequeno e médio porte, segundo o número de trabalhadores, que atuam em setores diferenciados. 
Essas empresas têm um importante papel na economia municipal, uma vez que empregam a maior parte da PEA do setor secundário, dinamizando o comércio e os serviços da cidade.

Assim, refletindo a intervenção do estado no espaço, o DI de Elói Mendes consiste em um espaço produtivo com uma dinâmica interna pouco expressiva, mas que possui uma grande importância para o município, tanto na geração de postos de trabalho, quanto pelo aquecimento das atividades comerciais e de serviços.

\section{Referências Bibliográficas}

AMORIM FILHO, Oswaldo Bueno et al. Os eixos de desenvolvimento em Minas Gerais e suas tecnopóles. In: ENCONTRO NACIONAL DE PRÁTICA DE ENSINO DE GEOGRAFIA, 5, 2000, Belo Horizonte. Mesas-redondas...Belo Horizonte: 2000, p. 35 - 49.

ASSEMBLÉIA LEGISLATIVA DE MINAS GERAIS. O Estado: municípios mineiros. Disponível em: <http://www.almg.gov.br/. Acesso em: 27 mar. 2006.

BESSA, Kelly Cristine F. O. et al. Dinâmica sócio-econômica das cidades locais situadas em áreas de cerrado mineiro. Caminhos da Geografia, Uberlândia, v. 3, n. 5, p. 9 - 29, fev. 2002.

BIAGGINI, José Glauco Carneiro. Elói Mendes: sua memória, sua gente. Varginha, 1999.

CARLOS, Ana Fani Alessandri. Espaço e indústria. São Paulo: Contexto, 2001.

COMPANHIA DO DESENVOLVIMENTO ECONÔMICO DE MINAS GERAIS.

Disponível em: <http://www.comig.com.br/>. Acesso em 15 jun. 2006.

COMPANHIA DOS DISTRITOS INDUSTRIAIS DE MINAS GERAIS. Disponível em: $<$ http://www.cdi.mg.gov.br/download.htm/>. Acesso em: 12 maio 2004.

CORRÊA, Roberto Lobato. O espaço urbano. 2 ed. São Paulo: Ática, 1993. 94 p.

FREITAS, Cláudia Maria de. Distrito industrial e organização do espaço urbano:_algumas reflexões a partir da cidade de Uberlândia. 1995. 120 f. Monografia (Bacharelado em Geografia), Instituto de Geografia, Universidade Federal de Uberlândia, Uberlândia, 1995.

GOVERNO DO ESTADO DE MINAS GERAIS. Cidades. Disponível em:

$<$ http://www.cidades.mg.gov.br/cidades/own/menuprinc $>$ Acesso em: 12 maio 2004. 
HISSA, Hélio Barbosa. Distritos industriais (ou clusters) como estratégia de desenvolvimento econômico local para o Brasil. 2003. Disponível em: <http://www. economiabr.net/colunas/hissa/clusters.html>. Acesso em 12 maio 2004.

INSTITUTO BRASILEIRO DE GEOGRAFIA E ESTATÍSTICA. Cidades@. Disponível em: < http://www.ibge.gov.br/cidadesat/default.php.>. Acesso em 12 maio 2005.

MARKUSEN, Ann. Áreas de atração de investimentos em um espaço econômico cambiante: uma tipologia de distritos industriais. Nova Economia, Belo Horizonte, v. 5, n. 2, p. 9 - 44, dez. 1995.

OLIVEIRA, Lúcia Helena Garcia de. Algumas considerações sobre a implantação de distritos industriais. Revista Brasileira de Geografia, Rio de Janeiro, v. 38, n. 4, p. 22 - 69, out/dez. 1976.

RODRIGUES, Maria Lúcia. Estrada, produção do espaço e expansão industrial. São Paulo: Loyola, 1983.

SAMPAIO, Sílvia Selingardi. A atividade industrial e a organização do espaço geográfico. Documentos Geográficos da ARGEO, Rio Claro, n. 16, 1988. 